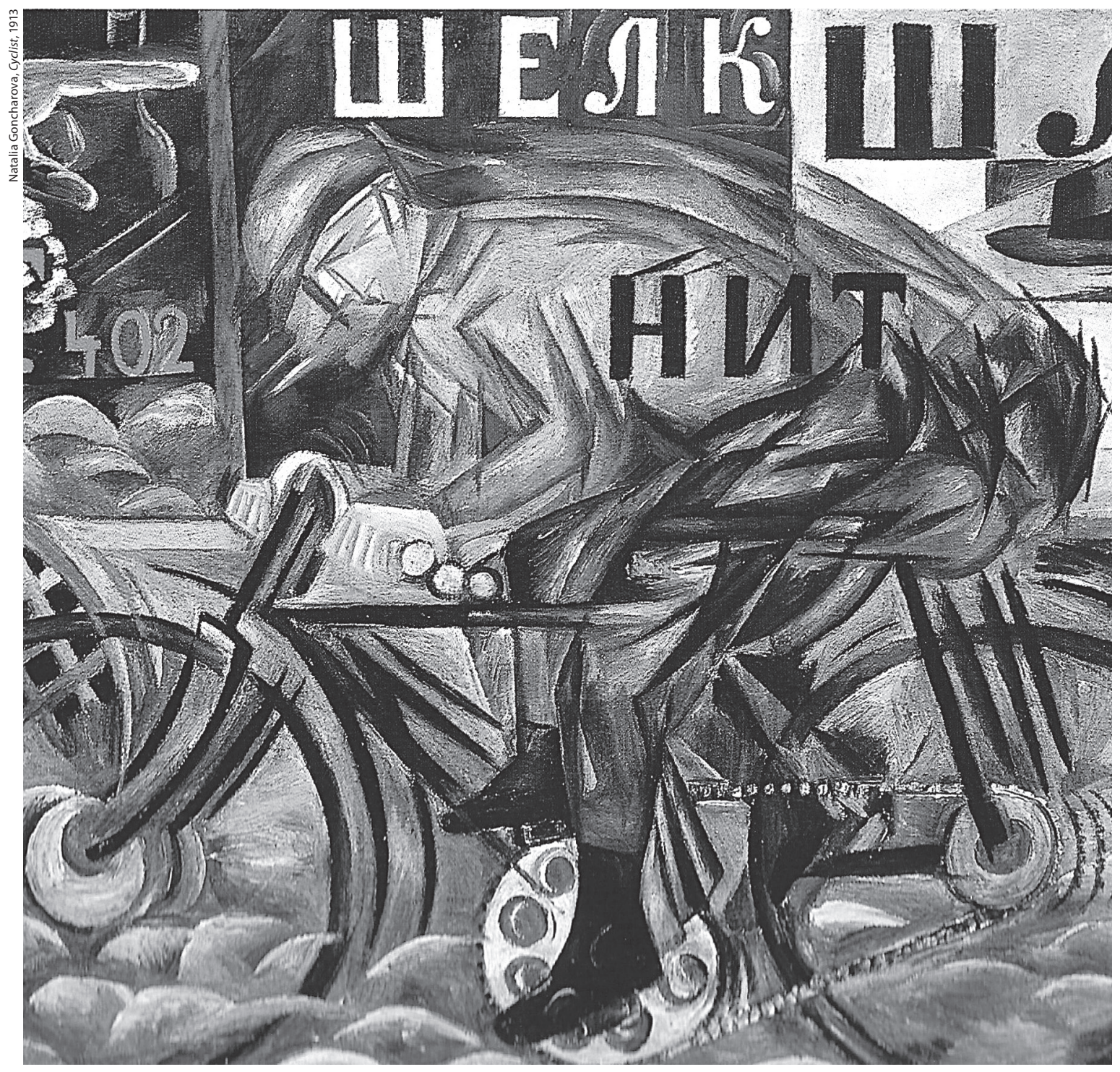

\title{
Apontamentos sobre Boris, Jerusa, \\ florestas de signos e afinidades eletivas
}

Gutemberg Medeiros 


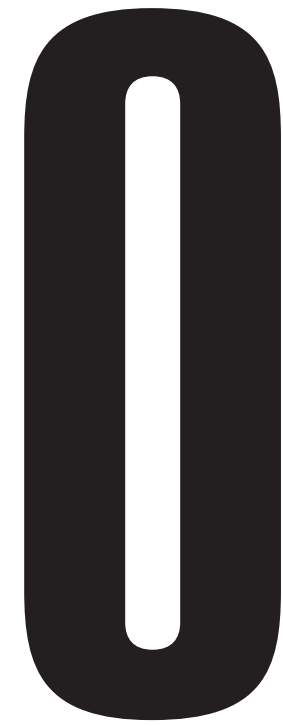

lho o telefone e não posso fazer o que tantas vezes fiz. Teclar para ouvir do outro lado da linha o "alô, boa tarde" característico e, em poucos momentos, começarmos a rir de alguma besteira. Ele não estará do outro lado da linha. Para conversar, recorro à memória e aos livros da estante. Boris Solomonóvitch Schnaiderman está aqui. Inclusive em sua letra miúda e um tanto trêmula. “- E aí, Boris, como vai esta força?"

Lembrar Boris é trazer à baila uma fortuna de nomes que pertencem às mais variadas áreas do conhecimento e atravessam arte, literatura e ciências da linguagem. Isso se deve especialmente aos avanços em ciências humanas a partir de sua atuação como professor do curso de Russo na USP desde 1960. Aqui pretendo - baseado em depoimentos checados em sua produção lembrar alguns momentos dessa contribuição no campo da chamada semiótica russa de Tártu-Moscou, sua amizade com V. V. Ivánov, que resultou no seu encontro com Jerusa Pires Ferreira, iniciando uma integração entre casamento e admiração intelectual mútua por mais de 30 anos.

Para Boris, 1968 foi o ano-chave, pois publicou a ampla coletânea Poesia russa moderna (Editora Civilização Brasileira), trabalhada com os irmãos Haroldo e Augusto de Campos, trouxe Roman Jakobson ao Brasil e depois começou longa relação de amizade com V. V. Ivánov, que também visitaria estas terras a seu convite.

Mas voltemos um pouco no tempo. Como se não bastasse, Haroldo de Campos volta da Itália e presenteia Boris com Dostoevskij: poetica e stilistica, versão do posteriormente mais conhecido Problemas da poética de Dostoiévski, de Mikhail Bakhtin, provocando-lhe uma "leitura reslumbrada" que perdurou décadas. Jakobson,

GUTEMBERG MEDEIROS é jornalista, pós-doutorando pela ECA/USP e professor do curso de graduação em Jornalismo da Universidade Estadual de Londrina. 
Ivánov e Bakhtin foram três autores que decidiram a vida intelectual de Boris.

Ao entrar na USP para abrir o curso livre de Russo em 1960, concorreu com um iugoslavo que apenas sabia a língua russa, sem envolvimento algum com a cultura. Boris, por sua vez, tinha vertido Tchékhov e possuía longa trajetória, da qual constava a colaboração da coluna "Letras Russas" no Suplemento Literário de $O$ Estado de S. Paulo, editado por Décio de Almeida Prado. Várias traduções suas anteriores jamais incluiu em seu currículo por serem assinadas com o pseudônimo Boris Solomonov, como revelei em entrevista com ele publicada na Revista USP em 2007.

Boris queria emprego fixo e trabalhar exclusivamente com literatura e tradução, mas foi informado, logo que começou, sobre a necessidade de ensinar teoria literária e linguística. A caminhada teórica de Boris estava em filosofia e teoria políticas. Por cinco anos, por exemplo, respondeu por curso de formação de quadros do PCB ensinando marxismo-leninismo para imigrantes. Além de cerca de uma década de cursos livres de filosofia e epistemologia, lecionados por Anatol Rosenfeld na casa de Jacó e Gita Ginsburg. Logo, literalmente passou a ler tudo o que encontrava pela frente, especialmente orientado pelo colega e amigo Antonio Candido.

Em meio à correria, descobriu a produção do linguista carioca Joaquim Mattoso Câmara Jr., ficando especialmente interessado na divulgação da arquitetura teórica de Roman Jakobson, que emergia como um dos mais destacados pensado- res da vertente estruturalista. Em dado momento, Boris telefonou, marcou encontro com Joaquim Mattoso e foi de ônibus ao Rio de Janeiro. Chegando lá, ficou encantado com a biblioteca e ampla bibliografia em inglês, francês e alemão de Jakobson, de quem fora aluno nos EUA durante a Segunda Guerra Mundial, sendo colega de turma com Claude Lévi-Strauss. O carioca preservava uma relação epistolar e mantinha-se informado sobre os avanços do antropólogo.

Boris passou a importar obras do pensador russo e prosseguiu em diálogo com Mattoso, o qual, perguntado se Jakobson teria interesse em vir ao Brasil, lhe informaria o endereço para fazer a consulta. Sem tardar, Boris enviou a Jakobson carta em russo propondo a visita e recebeu resposta entusiasmada, dizendo que há anos desejava vir ao país. Resultado: Jakobson veio ao Brasil em setembro de 1968 e fez palestras em São Paulo, Rio de Janeiro e Salvador, onde conheceu a estudante Jerusa Pires Ferreira. A partir dessa visita, Jakobson teve contato com editores brasileiros, como Jacó Guinsburg, da Perspectiva, e passou a ter obras suas publicadas aqui. Boris manteve amizade epistolar com o pensador até seu falecimento, em 1982.

A tradução de poetas russos com os irmãos Campos teve seu maior desafio em Velimir Khlébnikov. Praticamente inventou uma linguagem toda própria, levando a radicalidade da expressão a limites nunca vistos. Os tradutores/transcriadores se ressentiram de acesso a pouco material sobre o poeta. 
Dezembro de 1968 foi um marco na vida de Boris e de todo o país, quando, no dia 13, sexta-feira, foi baixado o Ato Institucional n. 5, suspendendo todos os direitos e impondo censura completa a todas as manifestações nos meios de comunicação de massa. A exemplo de outros momentos trágicos ou difíceis, Boris não se entregou ao estupor. Iniciou a sua longa resistência seguindo nas suas atividades de pesquisa.

Certo dia saiu de casa, passou pela Praça da República, quebrou na Rua Barão de Itapetininga e entrou em galeria na altura do número 275. Foi até o fim do corredor e entrou na Livraria Francesa. Foi recebido por um atendente que conhecia aquele professor da USP, que então começou a informar-lhe sobre as novidades. Logo se deteve ante o mais importante órgão do dominante estruturalismo francês e viu a manchete de capa da revista: "La sémiologie aujourd'hui en URSS". Abaixo, leu o título "Structure d'un poème de Khlebnikov". Ainda de pé na livraria, foi ter ao texto na página 9 , onde estava um dos poemas que mais deram trabalho na coletânea de poemas russos e ficou resolvido na genial transcriação de Haroldo de Campos:

"Eis-me levado em dorso elefantino, Palanquim no elefante virgem-fúmeo. Todas-me-amando, novo Vixnu, Tramam, miragem nívea, o palanquem".

Isso bastava. Boris comprou a revista, voltou para casa e se surpreendeu com o ensaio daquele professor que nunca ouvira falar antes, Viatchesláv Vs. Ivánov. Muito esclareceu sobre o poeta, mas abriu uma

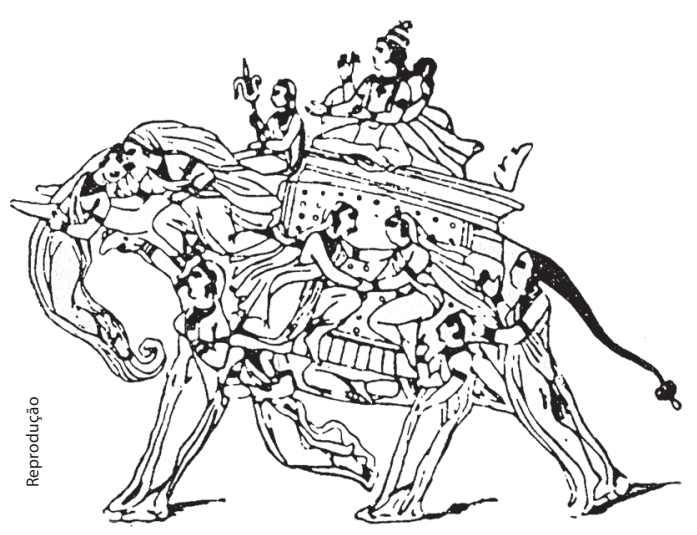

série de questionamentos. Em seu texto publicado nesse exemplar, Boris conta rapidamente sobre o contato. O que não explicitou é que na primeira correspondência elencou várias perguntas e recebeu, tempos depois, a resposta com um pacote enorme com várias publicações: exemplares de novas coletâneas do poeta e ensaios de outros pesquisadores recentemente editados. Aí começava uma grande amizade epistolar.

A segunda correspondência de Ivánov trouxe um pedido peculiar. Dizia ter um amigo que estudava há anos o carnaval desde a Europa através dos séculos e pedia matérias recentes sobre a manifestação no Brasil. O nome do interessado era Mikhail Bakhtin. Boris espantou-se, pois teve primeira notícia sobre este autor através da produção do estudioso Leonid Grossman, cuja coletânea de ensaios Dostoiévski artista traduziu (Civilização Brasileira, 1967) e, como já falei, recebera de Haroldo de Campos Dostoevskij: poetica e stilistica. Nessa troca de correspondência, cada vez mais, Boris passou a receber ensaios da escola de semiótica de Tártu-Moscou e seus pensadores tão diversos em abordagens e temas. 
A primeira vez que Boris e Ivánov se viram pessoalmente foi em Moscou, em 1972. Na introdução à coletânea Turbilhão e semente: ensaios sobre Dostoiévski e Bakhtin (inexplicável edição única desta preciosa seleta de ensaios), Boris o qualifica como "guia e companheiro comunicativo" - aludindo ao seu caráter solar extremante extrovertido e bem-humorado, quando não despachado, em contraste ao caráter reservado do professor da USP. Ivánov proporcionou-lhe dois momentos únicos. O primeiro foi propor uma visita a Bakhtin, à sua casa, em aldeia de escritores nas proximidades da capital russa. Boris pouco falou, pois só conhecia uma obra do pensador, mas registrou naquela mesma introdução momentos do que viu e ouviu entre os amigos russos:

"Lembro-me que Mikhail Mikháilovitch apanhou um livro encadernado, de capa azul, para mostrar a V. V. Ivánov: uma edição em fac-símile de obras em prosa do poeta simbolista Viatchesláv Ivánov, que saíra na Bélgica e que alguém lhe dera. Seus olhos, que me pareceram pequenos, brilhavam de alegria, como se estivesse descobrindo algo que procurara muito".

Anos depois, Jerusa Pires Ferreira extrovertida e solar como Ivánov - dizia que, no lugar de Boris, conversaria - e muito - com Bakhtin.

Ao sair do encontro com Bakhtin, Ivánov volta-se para Boris e pergunta se ele traduziu e escreveu ensaios sobre Maiakóvski no Brasil, e ele confirmou. O russo, ani- madamente, informou que logo ali morava Lília Brik, o grande amor do poeta. Boris gelou, e imagino-o a gaguejar não ser necessário incomodá-la, já que encontro algum tinha sido marcado com antecedência. Ivánov insistiu, sabia-se lá quando Boris teria outra oportunidade, e, dando as costas ao amigo, foi rumo à casa dela.

Boris o seguiu completamente sem jeito, muito envergonhado. Ivánov bateu à porta $\mathrm{e}$ Lília atendeu. Ele apresentou-se brevemente e falou de modo ostensivo do amigo brasileiro, professor de uma das maiores universidades das Américas, no Brasil, tradutor e ensaísta a divulgar a extensa obra de Maiakóvski e pedia-lhe excepcionalmente uma entrevista, pois estava em vias de voltar para casa. Boa parte desse diálogo com Lília e o seu então companheiro V. A. Katanian foi publicada como apêndice, entre outros materiais, à edição de poemas em traduções de Boris, Haroldo e Augusto de Campos (2006). Boris não conta no texto que, durante o diálogo, Lília mostrava edições e reproduções de fotos e as empilhava em mesinha próxima a ambos. Na hora das despedidas, ela olhou duramente para Boris e o repreendeu perguntando o porquê de não pegar todo aquele material separado, e divulgar no Brasil. Boris agradeceu e encheu os braços. Parte desse material está na coletânea de poemas de Maiakóvski.

Em seus cursos na USP e na PUC, os pensadores da semiótica da cultura também foram ventilados em trabalhos acadêmicos. A ponto de Boris ter orientado a dissertação de mestrado com tradução do original russo e análise de Estrutura do 


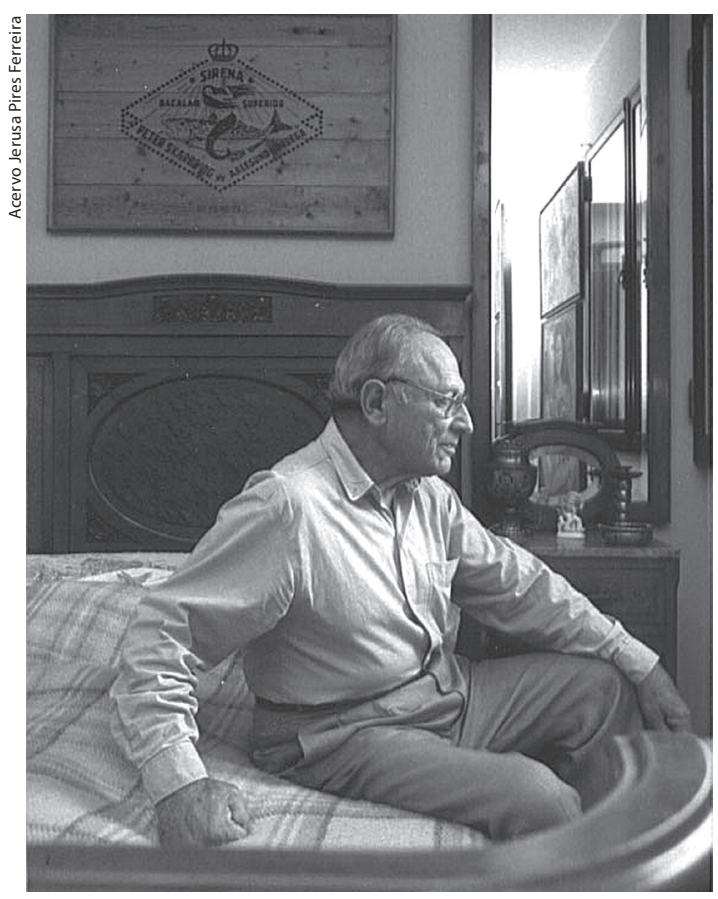

Boris Schnaiderman em sua residência em Higienópolis (SP), 2015

texto artístico, de Iuri Lotman, realizada por Jasna Paravich Sarhan no curso de Russo e defendida em 1978. Infelizmente, na mesma época foi publicada a edição portuguesa e os editores brasileiros não se animaram a publicar uma versão brasileira, mas o trabalho continua disponível na Biblioteca da FFLCH/USP.

O doutorado de Jasna foi a tradução integral e análise de Morfologia do conto maravilhoso, de Vladimir Propp - outro autor caro à escola de semiótica de Tártu-Moscou -, orientado por Boris. A publicação ainda trouxe à guisa de apêndices três textos de referência: "O estudo tipológico-estrutural do conto maravilhoso", de Eleazar Meletínski (outro pensador destacado de Tártu-Moscou), "A estrutura e a forma - reflexões sobre uma obra de Vladimir Propp", de Claude Lévi-Strauss, e "Estudo estrutural e histórico do conto de magia", de Propp.
Interessante observar o papel de Boris como orientador de trabalhos de pós-graduação. Quando era o caso de tradução de obras do russo, além da presença constante ao longo do trabalho, o fechamento do texto era realizado com o orientando lendo a versão em português e Boris acompanhando em russo. Logo que o orientador ouvia algo destoante, parava a leitura e discutia com o autor da versão até chegarem a bom termo. De certa maneira, Boris era coautor da versão. Extremamente rigoroso na condução dos trabalhos, era quando emergia o ex-sargento da FEB. Alguns orientandos chegaram a trocar de orientador por causa disso.

Certa vez, entrevistei Jacó Guinsburg e perguntei-lhe à queima-roupa: "Quem é Boris Schnaiderman?", quando já transcorriam mais de 50 anos de amizade e colaboração, especialmente de Boris com a Editora Perspectiva. Ele me olhou séria e fixamente um tempo, matutando profundamente. De repente, sorriu e declarou: "Na República Boris Schnaiderman, o Ministério da Guerra é estruturalista, mas a Casa Civil é Bakhtin". Talvez tenha sido a melhor definição, ou tradução, que já ouvi dele. Pois unia o rigor da pesquisa científica herdada dessa corrente de pensamento iniciada por Jakobson e Tinianov nos anos de 1920 - e tomou as ciências humanas nos decênios 1950 e 1960 - com o mundo do diálogo, riso e liberdade de pensamento do teórico russo assistemático que Boris conheceu em 1972.

Dessa viagem de 1972, Boris trouxe farto material teórico de semiótica da cultura e realizou o sonho de publicar a coletânea que organizara de Semiótica russa (1979), com traduções dele, Aurora Bernardini e Lucy Seki. Aqui o leitor percebe a amplidão de temas e abordagens dessa plêiade 
de pensadores. Percebe-se como Boris uniu o agradável ao agradável ao ter traduzido o ensaio "Sobre a estrutura dos signos no cinema", do amigo Ivánov, e, ao mesmo tempo, revelando a sua paixão por essa manifestação artística.

Mudança de plano rápida. Em 1977, uma jovem senhora desembarca em São Paulo com refinados figurinos e ampla bagagem diretamente para o apartamento temporário do Prédio E de pós-graduação do Conjunto Residencial da USP (Crusp). Jerusa Pires Ferreira cursou várias disciplinas com o melhor da intelectualidade como Umberto Eco, Uspenski,

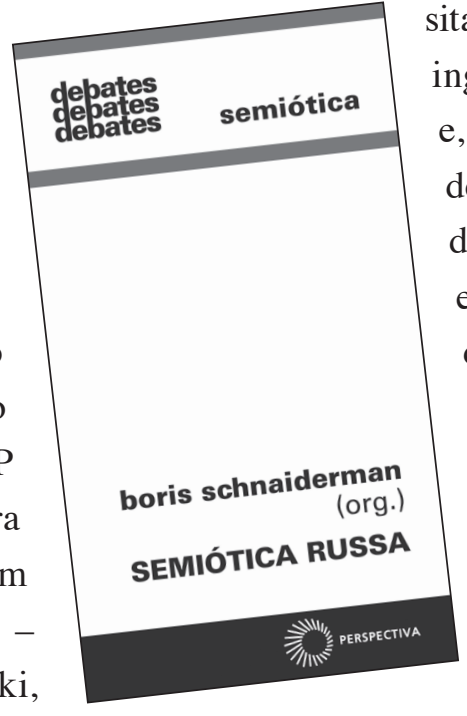
sitava em traduções reputadas em inglês, francês, italiano, alemão e, também, em romeno, a partir de contatos com pesquisadores dessa nacionalidade e colegas em Urbino. As várias afinidades intelectuais entre ambos, inclusive o ramo de mitopoética, fizeram nascer profunda amizade e admiração intelectual mútuas.

Essa relação intelectual que, posteriormente, evoluiu para o casamento foi determinante na vida de ambos. Um interagiu com o outro em diálogos e trocas profundas. Ou na produção de cada um ou em produções pensadas a quatro mãos, sempre tendo como uma das fundações básicas a floresta de signos redundando na decodificação de mundos e objetos estéticos e/ou intelectuais.

Concordo com Adriano Sousa ao afirmar que tem o dedo de Jerusa na produção de Boris a partir desse convívio. Ela tanto o incentivava a ousar "atos desmedidos" quanto dava sugestões preciosas nas leituras atentas. O leitor pode perceber isso em explicitações desse tipo de contribuição, por exemplo, na coletânea Tradução, ato desmedido (Perspectiva, 2001), onde cita soluções de Jerusa em traduções, mas também na excelência ensaística alcançada por Boris em $O s$ escombros e o mito.

Em contrapartida, na obra que demandou anos de pesquisas acuradas, Matrizes impressas do oral: conto russo no sertão, 


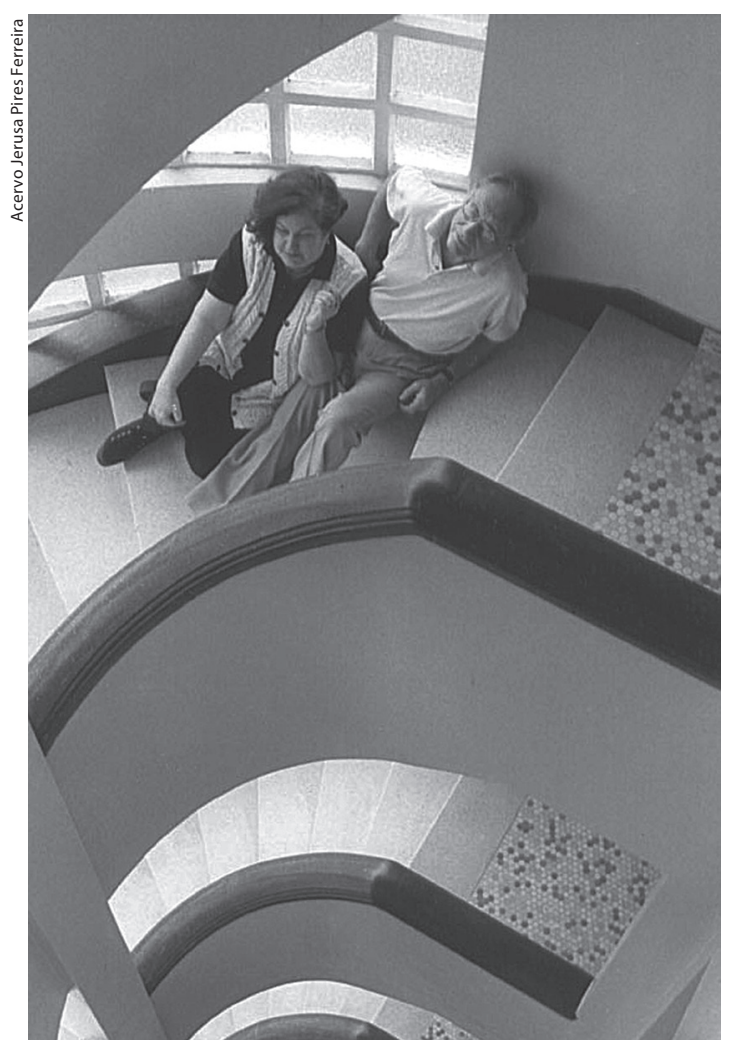

O casal Boris e Jerusa em São Paulo, 2015

Jerusa contou com a leitura atenta de Boris e colaboração nas traduções do russo de “Coze Saltan”, de Púschkin, e "Achik-Kerib (história turca)", de Lérmontov, peças-chave para as reflexões de Jerusa maturadas por anos em pesquisas realizadas em bibliotecas e acervos nacionais e do exterior lastradas em Vladimir Propp, pensadores de Tártu-Moscou, Jakobson, Freud, entre outros. Notável trabalho a quatro mãos foi a organização e tradução de Silêncio e clamor do poeta Guenádi Aigui (1934-2006), de expressão russa e nascido na Tchuváchia (república autônoma da então URSS).

Outros exemplos dessa parceria poderiam ser arrolados aqui, mas deixo ao leitor a oportunidade da busca e da descoberta. Venho no entanto a cometer outra inconfidência de quem privou da amizade de ambos por mais de dez anos. O machismo ainda dominante se projetava sobre o casal. Os que desconheciam a vasta produção de Jerusa se referiam a ela como "a esposa do professor Boris". Ele nada tinha a ver com tal reducionismo grotesco. Nos planos públicos ou privados, era recorrente ele citar Jerusa e suas opiniões e trabalhos. Não o fazia por carinho apenas, mas por incontida admiração da companheira, revelando o quanto ela contribuía com a sua constante visão de mundo. O mesmo movimento se percebia de Jerusa para com Boris. Isso quando não polemizavam entre si, sempre com bom humor.

Chegando nos arremates deste texto, lembro certa feita que, ao vê-los conversar sobre o amigo comum Ivánov, aflorou certa lembrança em Jerusa. Logo após a instalação da internet em banda larga na casa de ambos, Jerusa providenciou a primeira videoconferência com o russo, já então lecionando na UCLA. Começaram a conversar quando, de repente, ela percebeu que ele olhava algo atentamente atrás dela. Voltou-se e viu Boris paralisado olhando fixamente para a tela LCD. Ivánov, com seu bom humor característico, disparou em russo para Boris largar mão do estupor, pois não era ali manifestação sobrenatural. E todos caíram na gargalhada. Boris comentou a passagem lembrando ter ele nascido em 1917 e que, apesar de Jerusa haver informado sobre a videochamada, ele não imaginava realmente o que seria. De 
repente, lá estava Ivánov, na sala da casa dele, falando de São Francisco.

Como disse no início deste texto, olho o telefone e não posso fazer o que tantas vezes fiz. Teclar para ouvir do outro lado da linha o "alô, boa tarde" característico, para, em poucos momentos, começarmos a rir de alguma besteira. Ele e ela não estarão do outro lado da linha. Não mais as longas conversas regadas a chás, torradas com geleias ou mesmo os diversos sabores e aromas variados. Comentários dos mais comezinhos do cotidiano ou de leituras em andamento. Os prazeres mútuos, a leitura, a música, o cinema, entre outros.

Nos últimos tempos, os retrocessos sérios na política brasileira, o golpe de Estado legitimado pelo Legislativo e Judiciário eram temas e temores recorrentes. Eles se foram antes dos desmantelos e barbáries em curso. Ficariam muito tristes com o que posteriormente tomou o país. Porém, vivem nas páginas de livros e jornais. Ambos resistiram ao longo de suas vidas em momentos difíceis justamente lutando contra negacionismos e posturas anticientíficas no passado e fariam o mesmo agora. Boris e Jerusa, presentes.

\section{REFERÊNCIAS}

BAKHTIN, Michail Michajlovič. Dostoevskij: Poetica e stilistica. Torino, Einaudi, 1968.

GROSSMAN, Leonid. Dostoiévski artista. Rio de Janeiro, Civilização Brasileira, 1967.

MEDEIROS, Gutemberg. "Entrevista com Boris Solomónovich Schnaiderman". Revista USP, v. 75, 2007.

PIRES FERREIRA, Jerusa. Matrizes impressas do oral: conto russo no sertão. São Paulo, Ateliê, 2014.

PROPP, Vladimir. Morfologia do conto maravilhoso. Rio de Janeiro, Forense Universitária, 1984.

SCHNAIDERMAN, Boris; CAMPOS, Augusto de; CAMPOS, Haroldo de. Maiakóvski: poemas. 7a ed. São Paulo, Perspectiva, 2006.

SCHNAIDERMAN, Boris. Tradução, ato desmedido. São Paulo, Perspectiva, 2001.

SCHNAIDERMAN, Boris. Os escombros e o mito. São Paulo, Companhia das Letras, 1997.

SCHNAIDERMAN, Boris. Turbilhão e semente: ensaios sobre Dostoiévski e Bakhtin. São Paulo, Livraria Duas Cidades, 1983.

SCHNAIDERMAN, Boris (org.). Semiótica russa. São Paulo, Perspectiva, 1979. 